\title{
DÜŞÜK VE YÜKSEK OVER REZERVLİ VAKALARDA VEGF POLIMORFIZM SIKLIĞININ KIYASLANMASI
}

\author{
The Comparison of VEGF Polymorphism Frequency between Cases with Low and \\ High Ovarian Reserve
}

\section{Derya DEVECI ${ }^{1}$}

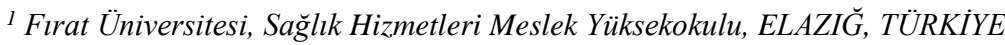

Amaç: Vasküler endotelyal büyüme faktörü (VEGF), overyan anjiogenezde kilit rol oynayan bir sitokindir. Biz de çalışmamızda düşük ve yüksek over rezervli infertil kadınlarda VEGF gen polimorfizminin over rezervi ile olası ilişkisini araştırmayı amaçladık.

Gereç ve Yöntemler: Bu çalışmaya, polikistik over sendromlu (PCOS) 64 kadın ile prematür overyan yetmezlikli (POF) 30 kadın dahil edildi. Periferik venöz kan örneklerinden elde edilen DNA'da polimeraz zincir reaksiyonu (PCR) yöntemi ile VEGF geni-2578 C/A tek nükleotid polimorfizmi (SNP) incelendi. İstatistiki analiz SPSS 16.0 programı ile yapıld1.

Bulgular: PCOS ve POF gruplarının ortalama yaş, vücut kitle indeksi, TSH ve prolaktin seviyeleri yönünden anlamlı bir fark yoktu. PCOS grubu için genotip dağılımı $\% 56.2 \mathrm{CC}$, \%26.6 CA ve \%17.2 AA iken, POF grubu için ise \%26.7 CC \%53.3 CA ve $\% 20$ AA idi. Gruplar arasında genotip frekansları bakımından farklılık saptand 1 ( $\mathrm{p}=0.018$ ). Mutant A allelinin, over rezervini minimal azaltıcı etkisi olduğu gözlendi $(95 \% \mathrm{CI}=0.12-0.22, \mathrm{OR}$ : $0.5, \mathrm{p}<0.01)$.

Sonuç: Çalışmamızda gözlediğimiz VEGF -2578 C/A polimorfizmindeki mutant A allelinin over rezervi üzerine olan etkisini tartışmak için genişletilmiş popülasyon çalışmalarına ihtiyaç vardır.

Anahtar Kelimeler: VEGF, polimorfizm, prematür overyan yetmezlik, polikistik over sendromu
Objective: Vascular endothelial growth factor (VEGF) is a cytokine playing key role in ovarian angiogenesis. We aimed to investigate the possible relation between VEGF gene polymorphism and ovarian reserve in infertile women suffering from either low or high ovarian reserve.

Material and Methods: This study was conducted on 64 women suffering from polycystic ovary syndrome (PCOS) and 30 women suffering from premature ovarian failure (POF). VEGF-2578 C/A single nucleotide polymorphism (SNP) was investigated with polymerase chain reaction (PCR) method on DNA extracted from peripheral venous blood sample. Statistical analyses were done using SPSS 16.0 programme.

Results: There was no significant difference between PCOS and POF groups for age, body mass index, TSH and prolactin levels. The genotype frequencies of PCOS and POF groups were respectively $56.2 \% \mathrm{CC}, 26.6 \% \mathrm{CA}, 17.2 \% \mathrm{AA}$ and $26.7 \% \mathrm{CC}$, $53.3 \%$ CA, $20 \%$ AA. There was a significant difference between groups for genotype frequencies $(p=0.018)$. We observed minimal negative influence of mutant $\mathrm{A}$ allele on ovarian reserve $(95 \% \mathrm{CI}=0.12-0.22$, OR: $0.5, \mathrm{p}<0.01)$.

Conclusion: We observed a minimal negative influence of VEGF-2578 C/A polymorphism on ovarian reserve. New and expanded population studies are needed to discuss our results.

Keywords: VEGF, polymorphism, premature ovarian failure, polycystic ovary syndrome 


\section{GíRiş}

Vasküler endotelyal büyüme faktörü (VEGF), vasküler geçirgenlik ve anjiogenezde görev yapan bir proteindir (1). Aylık overyan döngüde folliküler ve stromal anjiogenezde rol oynadığı gösterilmiştir (2). Perifolliküler kan akımının ve intrafolliküler oksijen düzeyinin idamesi ve kontrolü için VEGF önemli bir rol üstlenmektedir (3). Overyan primordial follikül havuzundan aylık ovulasyon döngüsüne girecek antral follikül (AF) sayısını belirleyen mekanizma günümüzde hala net olarak bilinmemektedir (4). Over rezervinin temel belirteçlerinden olan AF sayısı kimi kadında yüksek iken kimi kadında düşük olmaktadır (5). Yüksek AF sayısı polikistik over sendromu (PCOS) riskine, düşük AF sayısı ise prematür overyan yetmezlik (POF) riskine işaret etmektedir (6). Araştırmacıların bir kısmı VEGF geni tek nükleotid polimorfizmleri (SNPs) ile PCOS arasında güçlü bir ilişki olduğunu bildirirken; bir kısmı da PCOS ile VEGF arasında bir ilişki gözlemediklerini rapor etmişlerdir (1,7,8). POF, 40 yaş altı kadınlarda follikül stimülan hormon (FSH) düzeyinin 40 IU/L üzerine çıkması, estradiol düzeyinin düşmesi ve sekonder amenore ile kendini gösteren bir tablodur (9). Araştırmacılar VEGF polimorfizmi ile POF arasında ilişki gözlediklerini bildirmişlerdir (10).

$\mathrm{Bu}$ çalışmada yüksek over rezervli kadınlar ile düşük over rezervli kadınların VEGF geni SNP sıklığı açısından karşılaştırılması amaçlandı.

\section{GEREÇ VE YÖNTEM}

Bu çalışmaya Fırat Üniversitesi Hastanesi Tüp Bebek Ünitesi'ne Haziran 2012-Haziran 2013 tarihleri arasında başvuran PCOS tanısı konulan 64 infertil kadın ve POF tanısı konulan 30 infertil kadın lokal etik kurul onayı sonrası (Tarih:10.05.2012; Karar No: 09/04) dahil edildi. Over rezerv belirteci olarak AF kullanıldı. Menstrüel siklusun 3. günü yapılan transvajinal ultrasonografide tek overde AF sayıs 5 altında olanlar düşük over rezervli, tek overde AF sayısı 10 üzerinde olanlar yüksek over rezervli olarak kabul edildi. PCOS tanısı Rotterdam 2003 kriterlerine göre yapıld1. Oligoanovulasyon, hiperandrojenizm ve ultrasonografide tek overde periferik dizilimli 12 'den fazla AF varlığı kriterlerinden en az ikisini taşıyan 64 kadın hasta PCOS grubuna dahil edildi. POF grubuna ise 30 yaş altında en az iki kez adetin 3. günü (D3) bakılan FSH düzeyi 40 IU/L ve üzerinde çıkan, karyotip analizleri 46-XX olan ve overde AF izlenmeyen 30 kadın hasta dahil edildi. Tiroid gland disfonksiyonu, diabetes mellitus ve hiperprolaktinemisi olan hastalar çalışma dışı tutuldu. Tüm hastaların boykilo ölçümleri, D3 FSH, estradiol, tiroid stimulan hormon (TSH), prolaktin düzeyleri; PCOS hastaların ise bunlara ek olarak açlık glukoz ve insulin seviyeleri kaydedildi.

\section{Genotipleme ve SNP Seçimi}

Ön kol antekubital venlerinden alınan yaklaşık 5ml periferik venöz kan örneği antikuagülanlı tüplere konularak çalışılma vaktine kadar $-80{ }^{\circ} \mathrm{C}$ 'de saklandı. Çözdürme sonrası periferik venöz kan örneklerinden Wizard Genomik DNA Ekstraksiyon Kiti (Promega, ABD) üreticisinin belirttiği klavuza göre DNA elde edildi. Elde edilen DNA'da polimeraz zincir reaksiyonu (PCR) yöntemi (Applied Biosystem GeneAmp PCR System 9700, USA) ile VEGF geni$2578 \mathrm{C} / \mathrm{A}$ tek nükleotid polimorfizmi (SNP) araştırıldı. Primer dizileri;

\section{F: 5'-GGATGGGGCTGACTAGGTAAGC-3'}

\section{R: 5'-AGCCCCCTTTTCCTCCAAC-3'}

PCR $94^{\circ} \mathrm{C}$ 'de $5 \mathrm{dk}, 94^{\circ} \mathrm{C}$ 'de 35 siklus $30 \mathrm{sn}, 61^{\circ} \mathrm{C}$ 'de bağlanma, final basamak $72^{\circ} \mathrm{C}$ 'de $10 \mathrm{dk}$ olarak gerçekleşti. 324 bp'lik PCR ürünü, Bgl II restriksiyon enzimi ile $37^{\circ} \mathrm{C}$ 'de kesildi. Kesim ürünleri etidyum bromidli \%3'lük agaroz jelde yürütülerek $\mathrm{C}$ alleli için 324 bp, A alleli için 202+122 bp'lik bantlar görüntülendi (11).

Istatistiksel Analiz

İstatistiksel analiz SPSS 16.0 program ile yapıldı. Gruplar arasında sürekli değişkenler yönünden fark 
olup olmadığına datanın dağılım özelliğine gore student $\mathrm{t}$ test veya Mann Whitney $\mathrm{U}$ testi ile bak1lırken nominal verilerdeki fark yerine göre ki-kare veya Fisher exact test ile değerlendirildi. Polimorfizm ile over rezervi arasında ilişki olup olmadığına regresyon analizi ile bakıld1. Allel doz etkisi için 0, 1, 2 şeklinde mutant allelin kopya sayısına göre kodlama yapılıp, yaş ve vücut kitle indeksine (VKI) göre düzeltme yapıldıktan sonra lineer regresyon analizi yapıldı. p $<0.05$ değeri anlamlı kabul edildi.

\section{BULGULAR}

Hasta gruplarına ait demografik veriler Tablo 1'de karşılaştırılmış olup, gruplar arasında D3 FSH düzeyi dışında fark saptanmadı.

Tablo 1: Vakaların demografik özellikleri

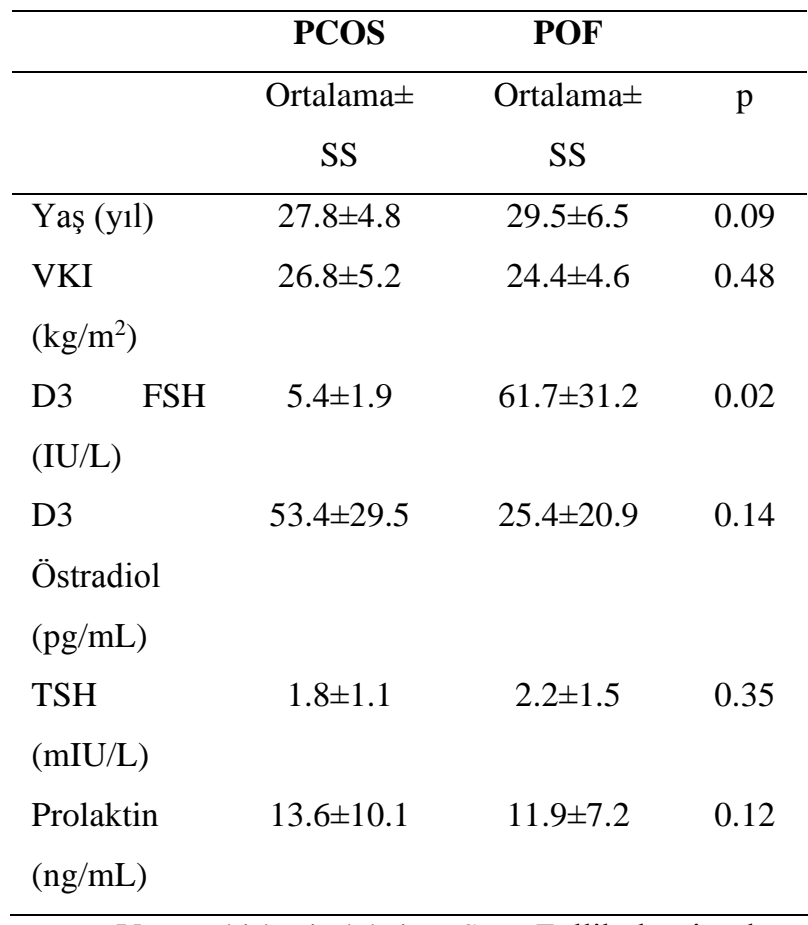

VKI= Vücut kitle indeksi; FSH: Follikül stimülan hormon; $\mathrm{TSH}=$ Tiroid stimülan hormon; $\mathrm{D} 3=$ Menstrüel siklusun üçüncü günü

PCOS grubu için genotip dağılımı CC \%56.2 (36/64), CA \%26.6 (17/64) ve AA \%17.2 (11/64); POF grubu için ise CC \%26.7 (8/30), CA \%53.3 (16/30) ve AA
\%20 (6/30) şseklinde idi. PCOS grubunda C allelinin frekansı \%69, A allelinin frekansı \%31 iken; POF grubunda $\mathrm{C}$ allelinin frekansı $\% 53$ ve $\mathrm{A}$ allelinin frekansı \%47 idi. PCOS grubunda dominant olan genotip CC iken, POF grubunda dominant olan genotip CA idi. Gruplar arasında genotip frekansları bakımından farklılık saptand $1(\mathrm{p}=0.018)$.

PCOS grubunun açlik glukoz ve insulin düzeyleri sirasiyla $89.7 \pm 18.1 \mathrm{mg} / \mathrm{dL}$ ve $15.1 \pm 11.4 \mathrm{mcU} / \mathrm{mL}$ idi. Açlık glukoz ve açlık insulin düzeyleri ile hesaplanan HOMA indeksi 2.5 değerinin üzerinde geldiğinde insülin direncinin (IR) bir göstergesidir. Ortalama HOMA-IR değeri 3.5 idi. Biz de PCOS hastalarını kendi içinde HOMA-IR değerine göre 2.5 altında olanlar ve $2.5=$ ve üstünde olanlar şeklinde iki gruba ayırdığımızda VEGF polimorfizm genotip frekanslarında farklılık saptamadık $(\mathrm{p}=0.28)$. VEGF2578 C/A SNP'sindeki mutant A allelinin over rezervi üzerindeki etkisi incelendiğinde; mutant allelin over rezervini minimal azaltıcı etkisi olduğu saptandı. $(95 \% \mathrm{CI}=0.12-0.22$, OR: $0.5, \mathrm{p}<0.01)$.

\section{TARTIŞMA}

Çalışmamız Türk kadın popülasyonunda VEGF-2578 C/A tek nükleotid polimorfizmi ile over rezervi arasındaki ilişkiyi gösteren ilk çalışmadır. VEGF-2578 C/A SNP frekansının PCOS ve POF grupları arasında anlamlı fark gösterdiğini tespit ettik. POF grubunda VEGF-2578 CA (heterozigot mutant) ve AA (homozigot mutant) genotiplerinin, PCOS grubunda da CC genotipinin daha yüksek frekansta olması dikkat çekici idi. Popülasyonumuzda VEGF-2578 C/A SNP'nin over rezervini azaltıcı yönde minimal bir etkisi olduğunu da gözledik. Güney Kore'de yapılan bir çalışmada 135 POF vakası kadın ile en az bir canlı doğum yapmış 120 sağlıklı kadında VEGF genine ait dört SNP (-2578 C/A, -1154G/A, -634G/C, 936C/T) frekansları araştırılmıştır. VEGF-1154 G/A polimorfizmi ile POF riski arasında anlamlı bir ilişki 
olduğu belirtilmiştir (9). VEGF-2578 C/A polimorfizminin, $1154 \mathrm{G} / \mathrm{A}$ ve $936 \mathrm{C} / \mathrm{T}$ polimorfizmleri ile ayrı ayrı birlikteliğinin POF gelişimi için anlamlı risk teşkil ettiği rapor edilmiştir (10). Biz de çalışmamızda VEGF -2578 C/A polimorfizminde mutant A allelinin over rezervine etkisi olduğunu gözledik.

VEGF oosit maturasyonunda ve implantasyonda önemli rol oynamaktadır (12). Bir meta-analizde VEGF gen polimorfizminin beyazlarda ve asyalılarda tekrarlayan gebelik kaybı ile ilişkili olabileceği belirtilmiştir (13). Boudjenah ve ark. tüp bebek uygulanan 428 kişilik bir kohortta VEGF +405 G/C polimorfizminin fertilizasyon, implantasyon ve gebelik oranlarını etkilediğini bildirmiştir (14). Bir başka çalışmada tekrarlayan implantasyon başarısızlığı olan 41 kadın hasta ile 130 sağlıklı gebelik eldesi olan kadında VEGF +405 G/C polimorfizm frekansları karşılaştırılmış. Mutant CC genotip frekans1 tekrarlayan implantasyon başarısızlığı olan grupta sağlıklı kontrollere göre anlamlı yüksek saptanmıştır (15). Over dokusundaki VEGF ekspresyon değişikliği folliküler gelişimle yakından ilişkilidir (16). Kong ve ark. yaptıkları hayvan deneyinde, VEGF ile muamele sonrası transplante edilen over dokusunda folliküler kaybın daha az olduğunu bildirmişlerdir (17). Araştırmacılar ratlarda preantral follikülden antral folliküle geçiş sürecinin VEGF ile ilişkili olduğunu göstermişlerdir (18). Almawi ve ark. 382 PCOS tanılı kadın ile 393 sağlıklı kadında VEGF genindeki 12 SNP frekanslarını karşılaştırmışlar. Sadece rs3025020 SNP minör allel frekansının PCOS grubunda anlamlı yüksek olduğunu gözlemişlerdir (7). Tunus'ta yapılan bir başka çalışmada 118 PCOS tanılı kadın ile 150 sağlıklı kadında VEGF polimorfizmi araştırılmıştır. rs3025039 (C/T) polimorfizminde CT genotipi ile PCOS fenotipi arasında iliş̧i gözlenmiştir (19). Hindistan'da yapılan bir başka çalı̧̧̧mada ise VEGF geni $+405 \mathrm{G} / \mathrm{C}$ polimorfizminde GG genotip ve $G$ allel frekansları PCOS'lu kadınlarda kontrol vakalarından anlamlı yüksek saptanmıştır (20). Biz çalışmamızda PCOS grubunda 2578 C/A SNP'sinde CC genotipi ve C allelinin frekansını daha yüksek gözledik. Vural ve ark. 137 PCOS vakasında VEGF -2578 C/A SNP'sini çalışmıştır. AA taşıyıcıları ile kıyaslandığında, $\mathrm{C}$ alleli taşıyanlarda glukoz/insulin oranının daha yüksek ve HOMA-IR'nin daha düşük olduğu bildirilmiştir (21). Bizim PCOS popülasyonumuzda insulin direnci olanlar ile olmayanlar arasinda VEGF -2578 C/A polimorfizm frekansı açısından bir farklı1ık gözlemedik. Bizim sonucumuzun, Vural ve ark. yaptığı çalışmanın sonucundan farklı olması popülasyonumuzun küçüklüğünden ileri gelebilir.

Arteriyel hipertansiyon ve obezitesi olan 95 perimenopozal kadın ile 20 sağlıklı perimenopozal kadında VEGF 634 G/C tek nükleotid polimorfizmi çalışılmış. GG genotipi arteriyel hipertansiyon ve obezitesi olan premenopozal kadınlarda, arteriyel hipertansiyonu ve obezitesi olan menopozal kadınlardan daha yüksek frekansta gözlenmiş. Perimenopozal hipertansif obez kadınlarda GG genotipinin kardiovasküler risk için bir belirteç olabileceği düşünülmüş (22). Wei ve ark. yaptıkları meta-analizde VEGF $405 \mathrm{G} / \mathrm{C}$ polimorfizmindeki C allelinin Asya ırkında immün aracılı inflamatuar hastalıklar için koruyucu rol oynarken, beyaz ırk için risk faktörü olabileceğini belirtmişlerdir (23). Chen ve ark. yaptıkları meta-analizde Asya 1rkında VEGF 634 $\mathrm{G} / \mathrm{C}$ polimorfizmi ile otoimmün hastalıklar arasında anlamlı bir ilişki saptamıştır (24). POF vakalarında \%4-30 oranında otoimmün mekanizmalar patogenezde rol oynamaktadır (25). Romatoid artritli hastalarda VEGF -2578 A/C polimorfizmindeki $\mathrm{C}$ allelinin kontrol vakalarından daha düşük bir frekans gösterdiği saptanmıştır (26). İlginç olarak VEGF polimorfizmi ırklara göre değişik sonuçlar doğurmaktadır. İtalyan 1rkında -2578 AA genotipi tip1 diabetes mellitusun gelişimini hızlandırırken; Finlandiya popülasyonunda 1154 GG genotipi ise tip1 diabetes mellitusun ortaya çıkmasına karşı geciktirici ve koruyucu etki 
göstermektedir (27). Biz de Türk popülasyonumuzda VEGF -2578 CA ve AA genotiplerinin POF ile ilişkili olduğunu gözledik.

Çalışmamızda hem PCOS hem POF gibi otoimmün alt yapısı olduğu düşünülen iki overyan patolojide VEGF polimorfizmini araştırdık. VEGF -2578 C/A polimorfizminin over rezervi üzerine negatif etkisi olduğunu gözledik. Çalışmamızdaki limitasyonlar kontrol grubunun olmaması ve PCOS grubunun sayı olarak az olmasıdır. Sonuçlarımızın daha sağlıklı tartışılabilmesi için kontrol grubu katılarak yapılacak genişletilmiş çalışmalara ihtiyaç duyulmaktadır.

Çıkar çatışması: Bu çalışmada yazar için herhangi bir çıkar çatı̧̧ması yoktur.

Teşekkür: Bu çalışmada emekleri geçen Dr. Zehra Sema ÖZKAN'a ve Dr. Raşit İLHAN'a teşekkür ederim.

\section{KAYNAKLAR}

1. Lee EJ, Oh B, Lee JY, Kimm K, Park JM, Baek KH. Association study between single nucleotide polymorphisms in the VEGF gene and polycystic ovary syndrome. Fertil Steril. 2008;89(6):1751-9.

1. Geva E, Jaffe RB. Role of vascular endothelial growth factor in ovarian physiology and pathology. Fertil Steril. 2000;74(3):429-38.

2. Van Blerkom J, Antczak M, Schrader R. The developmental potential of the human oocyte is related to the dissolved oxygen content of follicular fluid: association with vascular endothelial growth factor levels and perifollicular blood flow characteristics. Hum Reprod. 1997;12(5):1047-55.

3. Sukur YE, Kivançli IB, Ozmen B. Ovarian aging and premature ovarian failure. J Turk Ger Gynecol Assoc. 2014;15(3):190-6.

4. Fleming R, Seifer DB, Frattarelli JL, Ruman J. Assessing ovarian response: antral follicle count versus anti-Müllerian hormone. Reprod Biomed Online. 2015;31(4):486-96.
5. Monniaux D, Clément F, Dalbiès-Tran R, Estienne A, Fabre S, Mansanet C, et al. The ovarian reserve of primordial follicles and the dynamic reserve of antral growing follicles: what is the link? Biol Reprod. 2014;90(4):85.

6. Almawi WY, Gammoh E, Malalla ZH, Al-Madhi SA. Analysis of VEGFA variants and changes in VEGF levels underscores the contribution of VEGF to polycystic ovary syndrome. PLoS One. 2016;11(11):e0165636.

7. Vural P, Kusku-Kiraz Z, Dogru-Abbasoglu S, Cil E, Karadag B, Akgül C et al. Vascular endothelial growth factor $-2578 \mathrm{~A} / \mathrm{C},-460 \mathrm{~T} / \mathrm{C}$ and $+405 \mathrm{G} / \mathrm{C}$ polymorphisms in polycystic ovary syndrome. Eur J Obstet Gynecol Reprod Biol. 2009;147(1):57-60.

8. Shelling AN. Premature ovarian failure. Reprod. 2010;140(5):633-41.

9. Jeon YJ, Choi Y, Shim SH, Choi YS, Ko JJ, Yoon TK et al. Vascular endothelial growth factor gene polymorphisms in Korean patients with premature ovarian failure. Eur J Obstet Gynecol Reprod Biol. 2011;159(1):138-42.

10. Qing Liu, Yan Li, Jian Zhao, Dong-Lan Sun, YaNan Duan, Na Wang et al. Association of polymorphisms $21154 \mathrm{G} / \mathrm{A}$ and $22578 \mathrm{C} / \mathrm{A}$ in the vascular endothelial growth factor gene with decreased risk of endometriosis in Chinese women. Hum Reprod. 2009;24 (10):2660-6.

11. Chen X, Li A, Chen W, Wei J, Fu J, Wang A. Differential gene expression in uterine endometrium during implantation in pigs. Biol Reprod. 2015;92(2):52.

12. Sun Y, Chen M, Mao B, Cheng X, Zhang X, Xu C. Association between vascular endothelial growth factor polymorphism and recurrent pregnancy loss: A systematic review and meta-analysis. Eur $\mathbf{J}$ Obstet Gynecol Reprod Biol. 2017;211:169-76.

13. Boudjenah R, Molina-Gomes D, Torre A, Boitrelle F, Taieb S, Dos Santos E et al. Associations between individual and combined polymorphisms 
of the TNF and VEGF genes and the embryo implantation rate in patients undergoing in vitro fertilization (IVF) programs. PLoS One. 2014;9(9):e108287.

14. Boudjenah R, Molina-Gomes D, Wainer R, de Mazancourt P, Selva J, Vialard F. The vascular endothelial growth factor (VEGF) $+405 \mathrm{G} / \mathrm{C}$ polymorphismand its relationship with recurrent implantation failure in women in an IVF programme with ICSI. J Assist Reprod Genet. 2012;29(12):1415-20.

15. Yang M, Wang L, Wang X, Wang X, Yang Z, Li J. IL-6 Promotes FSH-induced VEGF expression through JAK/STAT3 signaling pathway in bovine granulosa cells. Cell Physiol Biochem. 2017;44(1):293-302.

16. Kong HS, Lee J, Youm HW, Kim SK, Lee JR, Suh CS, Kim SH. Effect of treatment with angiopoietin2 and vascular endothelial growth factor on the quality of xenografted bovine ovarian tissue in mice. PLoS One. 2017;12(9):e0184546.

17. Torres-Ortiz MC, Gutiérrez-Ospina G, GómezChavarín M, Murcia C, Alonso-Morales RA, Perera-Marín G. The presence of VEGF and Notch2 during preantral-antral follicular transition in infantile rats: Anatomical evidence and its implications. Gen Comp Endocrinol. 2017;249:8292.

18. Ben Salem A, Megdich F, Kacem O, Souayeh M, Hachani Ben Ali F, Hizem $S$ et al. Vascular endothelial growth factor (VEGFA) gene variation in polycystic ovary syndrome in a Tunisian women population. BMC Genomics. 2016;17(9):748.

19. Guruvaiah P, Govatati S, Reddy TV, Lomada D, Deenadayal M, Shivaji $S$ et al. The VEGF +405 G>C 5' untranslated region polymorphism and risk of PCOS: a study in the South Indian Women. J Assist Reprod Genet. 2014;31(10):1383-9.

20. Vural P, Kusku-Kiraz Z, Dogru-Abbasoglu S, Cil E, Karadag B, Uysal M. Vascular endothelial growth factor $+405 \mathrm{G} / \mathrm{C},-460 \mathrm{~T} / \mathrm{C}$ and $-2578 \mathrm{~A} / \mathrm{C}$ polymorphisms are not associated with insulin resistance in polycystic ovary syndrome. Int $\mathbf{J}$ Immunogenet. 2010;37(4):239-43.

21. Iaresko M, Kolesnikova E. The role of polymorphism 634 G/C (rs2010963) of VEGF-A gene in the development of hypertension and obesity in premenopausal women. Georgian Med News. 2016;256:33-7.

22. Wei N, Chen Z, Xue Z, Zhu Y. Polymorphism of VEGF gene in susceptibility to chronic immunemediated inflammatory diseases: a meta-analysis. Rheumatol Int. 2015;35(8):1351-60.

23. Chen H, Zhang T, Gong B, Cao X. Association between VEGF -634G/C polymorphism and susceptibility to autoimmune diseases: a metaanalysis. Gene. 2015;558(2):181-6.

24. Ebrahimi M, Akbari Asbagh F. The role of autoimmunity in premature ovarian failure. Iran $\mathbf{J}$ Reprod Med. 2015;13(8):461-72.

25. Paradowska-Gorycka A, Pawlik A, RomanowskaProchnicka K, Haladyj E, Malinowski D, Stypinska $B$ et al. Relationship between VEGF gene polymorphisms and serum VEGF protein levels in patients with rheumatoid arthritis. PLoS One. 2016;11(8):e0160769.

26. Del Bo R, Scarlato M, Ghezzi S, Maestroni A, Sjölind L, Forsblom C et al. VEGF gene variability and type 1 diabetes: evidence for a protective role. Immunogenetics. 2006;58(2-3):107-12. 